\title{
Optics education through the Arizona Galileoscope program
}

Stephen Pompea, Robert Sparks, Constance Walker, Erin F. Dokter

Stephen M. Pompea, Robert T. Sparks, Constance E. Walker, Erin F. C. Dokter, "Optics education through the Arizona Galileoscope program," Proc. SPIE 8481, Optics Education and Outreach II, 84810F (15 October 2012); doi: $10.1117 / 12.931007$

SPIE Event: SPIE Optical Engineering + Applications, 2012, San Diego, California, United States 


\title{
Optics education through the Arizona Galileoscope program
}

\author{
Stephen M. Pompea ${ }^{a}$, Robert T. Sparksa, Constance E. Walkera, and Erin F. C. Dokter ${ }^{b}$ \\ ${ }^{a}$ National Optical Astronomy Observatory, 950 N. Cherry Avenue, Tucson AZ USA 85719 \\ ${ }^{\mathrm{b}}$ Office of Instruction and Assessment, The University of Arizona, 1500 E. University Boulevard, \\ Tucson AZ USA 85721
}

\begin{abstract}
The National Optical Astronomy Observatory, in collaboration with Science Foundation Arizona and the Arizona public schools, has initiated a program of optics education that has been implemented in the Arizona cities of Flagstaff, Yuma, and Safford. A program is planned for Globe, Arizona and several other locations. The program is aimed at 5th grade teachers and students. It relies on NOAO-developed optics teaching kits designed around the Galileoscope student telescope kits. The program is designed to reach every 5 th grade teacher and every 5 th grade student in each city. Professional development is provided for the teachers using the NOAO-developed "Teaching with Telescopes" optics teaching kits which are given to each teacher. Each 5th grade student is part of a team building a Galileoscope and receives additional training on how to use the Galileoscope during the day or night. At the end of the training period a large star party is held for all of the students, their families, and their friends. The program is evaluated through the University of Arizona. This model has been successfully implemented during the past two years and we are exploring national replication. This program provides a cost-effective way to inject optics into the schools in an attractive, citywide program model. The talk will discuss the model in detail and some of the mistakes we have made as we have tested the model.
\end{abstract}

Keywords: optics education, educational systems, educational reform, technology education, outreach

\section{INTRODUCTION}

The staff of the Education and Public Outreach Department of the National Optical Astronomy Observatory is continuously exploring new ways to reach diverse audiences through its educational programs. Some of the efforts have involved citizen science programs ${ }^{1}$, informal science education kits in optics ${ }^{2}$, and special year-long celebrations of science $^{3}$. Other approaches have involved studies of educational resources ${ }^{4}$, creation of books for teachers ${ }^{5}$ and pedagogical content knowledge ${ }^{6}$, alignment with national education resources ${ }^{7}$, and creation of teaching kits ${ }^{8}$. Other efforts have been involved in understanding cross cultural factors ${ }^{9}$, optics misconceptions ${ }^{10}$, the use of formative assessment probes in optics education ${ }^{11}$, the creation of a high-quality student telescope ${ }^{12}$, design of programs to teach illumination engineering ${ }^{13}$, and teaching. Most of these efforts are national and international in nature.

This paper describes how we build upon these efforts in order to improve science education in Arizona, a topic touched upon in a previous paper ${ }^{14}$. The Arizona Galileoscope program seeks to combine outreach to elementary schools and professional development of teachers with a community-oriented program.

\section{PROGRAM RATIONALE: THE STATE OF SCIENCE EDUCATION IN ARIZONA}

The State of Arizona has outstanding resources available in the area of optical engineering education, particularly at the University of Arizona in Tucson. The University of Arizona is a leader in the optical sciences, astronomy, astronomical instrumentation, and the planetary sciences and has led a number of NASA astronomy and planetary science missions. Arizona is home to the world's largest collection of optical telescopes at Kitt Peak National Observatory, run by the National Optical Astronomy Observatory (NOAO). NOAO is a federally-funded research and development center and a nationally respected center for science education, with specialties in astronomy and optics education. Another 
educational resource is Science Foundation Arizona that provides funds for technology incubation and technology education in Arizona. The Arizona Optics Industry Association is a professional association of companies that also has a strong interest and commitment to optics education.

These educational resources must be placed in the context of the state of Arizona education. A 2008 report $^{15}$ by the Arizona Department of Commerce Aerospace and Defense Committee gives this pessimistic assessment of Arizona educational quality:

"Arizona graduates only $75 \%$ of its high school students, compared with a national average of over $85 \%$, and ranks 49th in the nation [in this category]. Arizona's economic future depends on the quality of our workforce - it's the number one priority for businesses considering expansion or location. A highly skilled workforce, supported by a well-developed community college and university system, allows companies to produce goods and services marked by innovation, knowledge and quality."

When this report was written in 2008, Arizona was also ranked among the lowest of all the states in per pupil expenditure. In the U.S. this number is highly correlated to the high school graduation rate. The Arizona Galileoscope program was designed as a response to these statistics on the quality of education in Arizona. For science education, the situation may even be worse. Elementary education under the No Child Left Behind Act demands a focus on reading and math and not science. In many schools, science education is being neglected and needs some stimulation. The Arizona state standards make $5^{\text {th }}$ grade an excellent grade level on which to concentrate effort in astronomy. This is also an ideal age to develop astronomy concepts.

Our model has five major components. First, we offer professional development on optics and astronomy to the teachers in selected Arizona cities. We try to target an entire city and have picked $5^{\text {th }}$ grade students as our target audience.

These students then learn optics concepts through a variety of experiments and activities that can be done in class with these teachers. They then build Galileoscopes and learn the parts of a telescope and their function. We assist in final preparations for the star party, such as how to point and focus the telescopes, through the use of practice sessions held the week before the star party. Finally we organize and assist at the large star party itself. These five stages last approximately half of a school year and require intensive involvement from NOAO EPO staff.

\section{THE GALILEOSCOPE}

To excite interest in astronomy we use the Galileoscope telescope. The Galileoscope is a high-quality, low-cost telescope kit developed for the International Year of Astronomy $2009^{16}$. It was developed specifically for students by a team of leading science educators, astronomers, optical engineers, mechanical designers, and manufacturing experts ${ }^{17}$. The telescope is easy-to-assemble, has a 50-mm (2-inch) diameter objective lens, and can magnify from 25- to 50-power using an achromatic lens system. Both the objective and the Plossl eyepiece are achromatic. The telescope is very sturdy and is designed to be put together and taken apart many times. It needs to be used with a tripod. It enables students at any urban or rural location to see what Galileo Galilei first saw 400 years ago, only with much better image quality. The telescope provides excellent views of lunar craters and mountains, the four Galilean satellites circling Jupiter, the phases of Venus, Saturn's rings, and countless stars that are invisible to the unaided eye.

The Galileoscope was specifically designed for use in cities and has proven to be a versatile urban star party telescope. Testing of the telescope at sidewalk astronomy events have occurred in New York, Paris, Boston, San Francisco, San Diego, and Washington DC, for example. An early prototype star party was held in the center of downtown Phoenix, next to the state capital. The Galileoscope was part of the first ever White House Star Party (October 7, 2009) organized by NASA, as part of the International Year of Astronomy 2009..$^{18}$

This program was designed to place Galileoscopes in the hands of students in different areas of Arizona. The program has gone to Flagstaff, Yuma, Safford, and Globe, Arizona. 

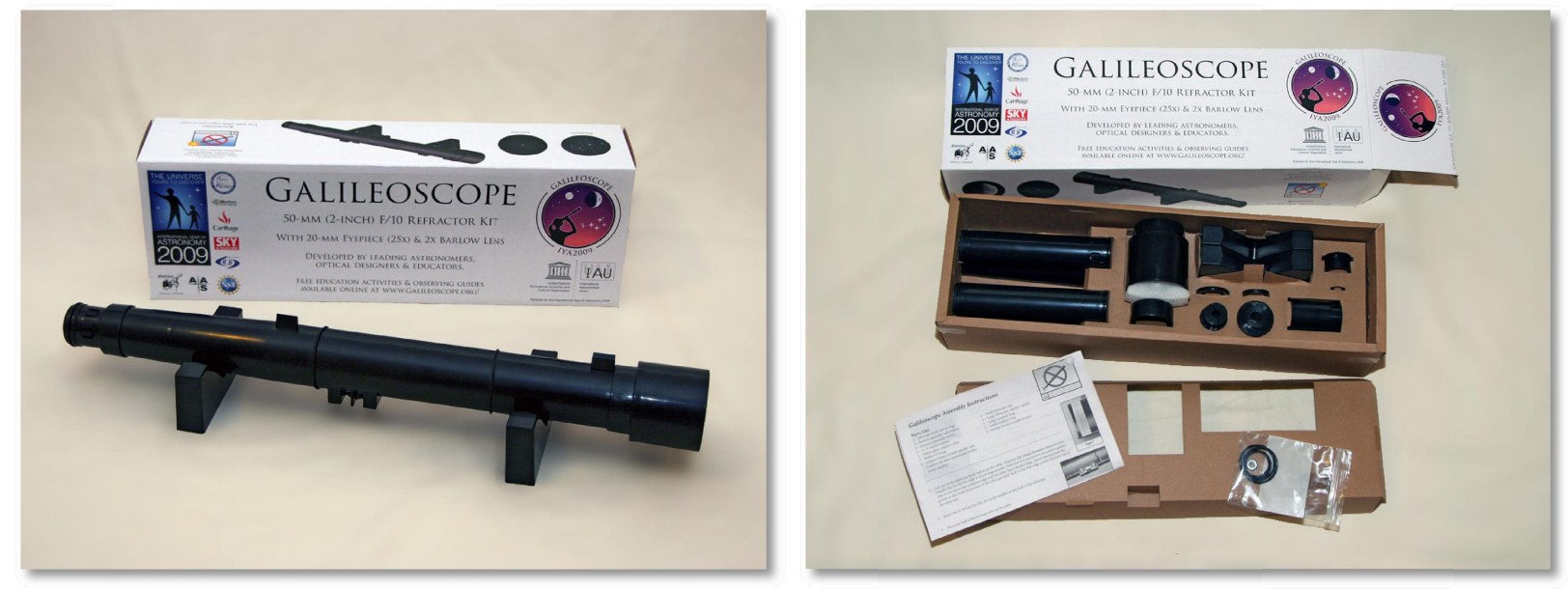

Figure 1: Left: Assembled $50 \mathrm{~mm} \mathrm{f} / 10$ Galileoscope, on its display stand, which also helps the telescope function as an optical bench for certain types of optics experiments. Right: Unassembled Galileoscope telescope kit. The telescope can be repeatedly assembled and disassembled without tools. It is durable enough for years of classroom use.

\section{PROFESSIONAL DEVELOPMENT FOR TEACHERS}

The first step in the program is to meet with school administrators and teachers to design a program localized and responsive to the needs of a city or school district. Then a date for a professional development workshop is set. This is typically a one-day workshop though in some cases it was repeated to allow teachers to attend who couldn't make the first workshop. A two-day workshop would be desirable but it is difficult to find time for teachers to participate in professional development on one topic for two days.

Some of the activities developed at NOAO in the Hands-On Optics program that are suitable for the professional development program are given below. The activities stress basic aspects of refraction, forming images using one or two lenses and the basic properties of a telescope. These activities were originally developed for the Hands-On Optics program.

- Refraction of Light Through an Acrylic Block

- Light Passing Through a Convex Lens

- $\quad$ Finding Lens Focal Lengths Using a Distant Object

- Simple Magnifiers

- Experiments in Arranging Lenses

- Refracting Telescope: Functions of the Eyepiece

- Measuring Resolution and Other Properties

Once the basics of optics have been addressed through participatory, inquiry-oriented activities, the workshop addresses the practical aspects of building and using a Galileoscope, running a star party, and observing astronomical objects.

In order to achieve widespread acceptance by classroom teachers, the optics activities are linked to the national science education standards, the national technology education standards, and the National Council of Teachers of Mathematics standards. The teacher's guide also has other items that are especially useful to a classroom teacher. These include a glossary and a list of optics misconceptions. An accompanying observing guide is also given. It describes which astronomical objects are most easily visible each month. Both the Galileoscope Optics Teaching Guide and the Galileoscope Observing Guide are available in pdf format at www.teachingwithtelescopes.org, a support web site for educators. "Teaching with Telescopes" is an NOAO project to provide instructional materials development, teacher professional development, and programs on using small telescopes to use excite children about science. 


\section{GALILEOSCOPE TEACHING KIT}

The professional development workshop trains teachers. To encourage them to use the activities we developed a classroom kit of materials that is provided free to the teachers attending our workshops in each city. These kits are designed to serve an entire class of students. Since teachers are trained around these instructional materials, they are encouraged to use them in the classroom as soon as they can. These kinds of activities that involve experimentation have advantages over the more conventional presentations and can promote gains in student learning by developing inquiry skills, and appreciation of the scientific enterprise, through an emphasis on problem solving, critical thinking, and collaborative learning. ${ }^{19}$

These materials in these kits are robust in order to survive the classroom environment.

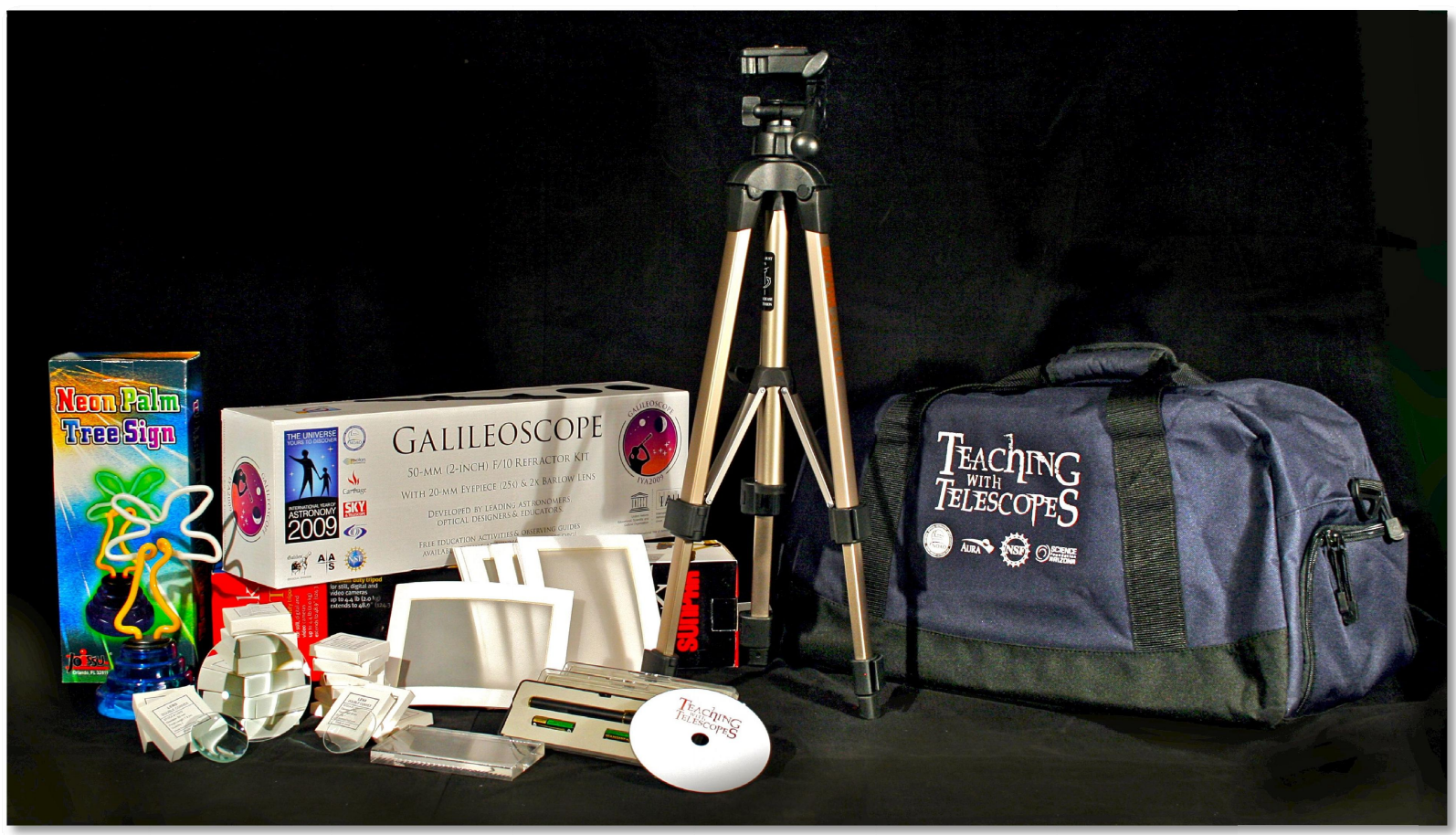

Figure 2: Classroom Kit for Teachers. The "Teaching with Telescopes" kit includes two Galileoscope student telescopes, two high quality tripods, a classroom set of lenses of short and long focal lengths, and a large double convex demonstration lens. It also includes demonstration lasers, vellum screens, an asymmetrical colored light source, a DVD of printable classroom activities, and a Lucite block that can be used to demonstrate refraction. This kit represents a smaller (and less expensive version) of the Hands-On Optics Module 3 teaching kit developed at NOAO with assistance from the Optical Society of America and SPIE.

\section{THE STAR PARTY}

The students participate in optics activities in class and then build the Galileoscope. For collaborative learning, a group of three students per Galileoscope is ideal. This group will build and use the telescope together. After the telescopes are built, the students learn to use the tripod. These activities can be done first in the daytime as part of their school activities. After practice during the day the students are able to sight and aim objects at night, including fainter objects such as star clusters and nebulae. 

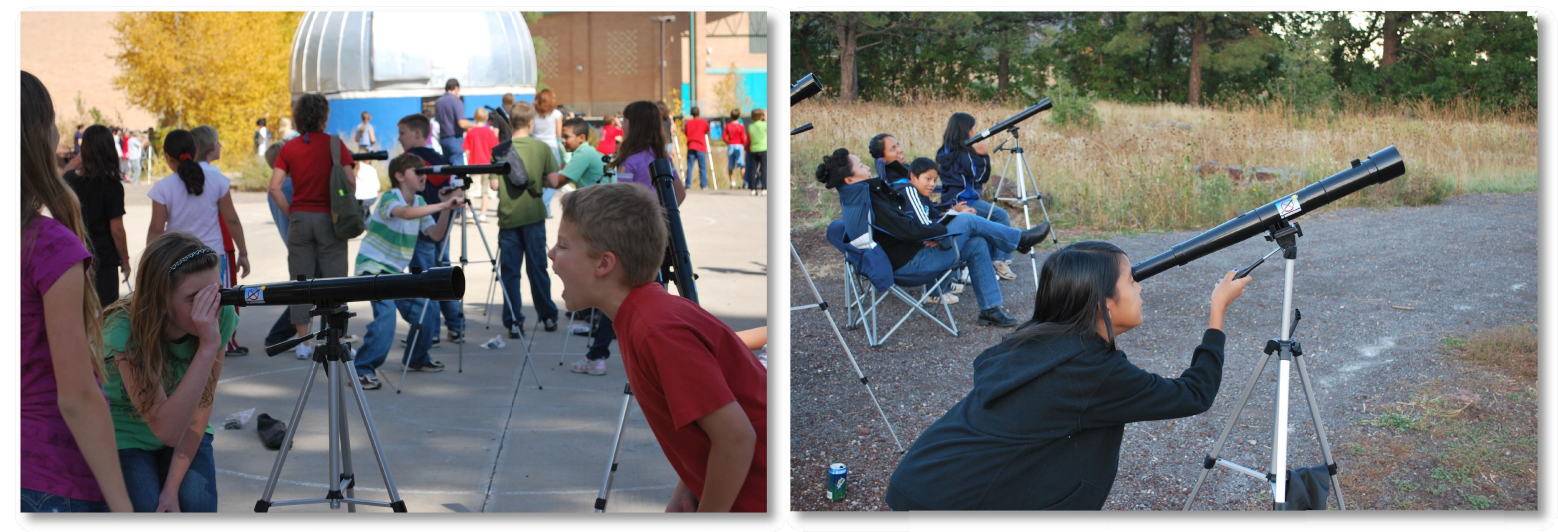

Figure 3: Left: Flagstaff students training on how to use the Galileoscope through daytime activities. This included pointing the telescope, the use of the tripod, and occasional play with the telescope! Right: Small group of students and their families using the Galileoscope at the Flagstaff Star Party. Over 400 attendees observed the Moon, Jupiter, open clusters, globular star clusters, and the Andromeda galaxy.

In collaboration with Science Foundation Arizona, the first star party was held at the Arizona state capitol complex in Phoenix as a proof of concept. The party went very well and the city lights were not an impediment to observing the moon and planets. On October 15, 2010, a star party was held in Flagstaff and attended by hundreds of students and their families. The location this time was a city park outside of town. On April 15, 2011 Yuma, Arizona hosted a similar star party for hundreds of $5^{\text {th }}$ grade students at Otondo Elementary School on the north edge of town and a similar star party was held at Discovery Park, an informal science center east of Safford, Arizona on May 17, 2012.

The format for each star party is roughly the same with the students organized by classes and observing with their teachers. A list of objects that can be seen is distributed and students receive stickers that can be put on a card after they observe an object. At the end of an evening a raffle is held for binoculars or other prizes. The star party lasts a few hours after sunset.

\section{OVERALL RESULTS TO DATE}

An evaluation of the program was conducted at each location. This included an evaluation of each part of the overall program: 1) the professional development training, 2) the classroom Galileoscope builds and NOAO staff visits with students in the classroom, and 3) the star party itself. Feedback was collected through teacher surveys, observations at schools during NOAO staff visits and during the star parties, and on-site interviews of teachers, students, parents, and school and community officials at the star parties. Each one of these education and public outreach events, as part of the overall Arizona Galileoscope program, was very positively received by program stakeholders - teachers, school and community leaders, students, parents, and NOAO staff.

Based on survey responses of participating teachers, the majority reported that the Galileoscope training workshop was an effective professional development experience and the Teaching with Telescopes curriculum is of high-quality. One representative teacher in Yuma asserted, "I enjoyed the hands-on workshops. I believe that is how our students learn far better by doing activities. The astronomers were clear. The activities made the learning fun and interactive." Further, teachers reported that they were not very familiar with using telescopes or with the related scientific concepts of light prior to the workshop, but that the workshop helped them become more familiar and gain facility with these concepts and use of telescopes.

The school Galileoscope builds and subsequent NOAO staff visits to help facilitate students' learning how to use the telescopes and tripods generated a great deal of excitement among students about telescopes and telescope-related optical science. It is estimated that nearly 3,000 Arizona $5^{\text {th }}$ grade students were involved with telescope-building and use in their classrooms across these three locations. The key challenges identified by teachers in building and using the telescopes in the classroom were the length of time required to build them (significantly over the 45-50 minutes anticipated) and checking the builds of each student team with limited adult support (e.g., "It was very difficult checking the lens setup for each telescope."). NOAO staff noted that most of the telescopes they looked through or worked with 
at the star parties following these telescope builds were correctly assembled, indicating the success of the classroom building sessions.

Approximately 480, 550, and 375 people were in attendance at the peak of the Star Parties in Flagstaff, Yuma, and Safford, Arizona, respectively. It was common to walk by a child and parent(s) with a telescope and hear children announcing, "I saw the moon!" or "I saw Jupiter!" There were also widespread comments from parents and teachers about how much enjoyment the children and they experienced during the event. Parents and teachers were also heard expressing pride in their children when they were able to successfully use the telescope or tell them what they had learned about astronomy and optical science. Throughout each of the events, even after two hours of observing, there was a high-level of excitement and enjoyment expressed by children and families. As one teacher stated, "The Star Party really brought the community together to enjoy something very spectacular....the gorgeous moon, planet Saturn, the stars, and the calmness of a peaceful evening being shared with awesome astronomers." Teachers also reported that their students were learning a great deal about science through this program, enough to teach them and their parents (e.g., "It was a great learning experience for me as a teacher and for the kids to get the chance to "show me" what they found and where they found it; they got to teach me!").

This program required significant labor on the scheduled dates, and the necessity for effective long-term planning and effective communication among stakeholders to recruit teachers, schedule school visits and arrange for the star party location, and communicate with parents about the star party, particularly as initial star party dates at Yuma and Safford had to be rescheduled due to inclement weather. However, the educational rewards, particularly for teacher professional development and enhancement of the science curriculum for underserved schools, was substantial. As one Flagstaff teacher stated, "We're a Title 1 school, out of 29 kids, 24 are free lunch. These opportunities for them are great, and we didn't need to have any bake sales to pay for it." The success of this effective, all-inclusive professional developmentschool outreach-community outreach program can be attributed to the extensive planning and preparation between NOAO staff and community representatives, motivated and collaborative teacher, school, and community partners, and conducive communities and schools.

\section{CONCLUSION}

The Arizona Galileoscope Star Party program represents an effective model to introduce optics and astronomy in a costeffective and time-effective way into elementary schools. The evaluation results indicate the value of the program to many aspects of science teaching in the elementary grades. Future star parties are being planned for all of the previous locations, beginning in the fall of 2012.

\section{Acknowledgements}

The National Optical Astronomy Observatory is operated by the Association of Universities for Research in Astronomy (AURA), Inc. under a cooperative agreement with the National Science Foundation. The Arizona Star Party programs were also supported by Science Foundation Arizona.

\section{REFERENCES}

\footnotetext{
1 Walker, C. E., Pompea, S. M., and Isbell, D., "GLOBE at Night 2.0: on the Road Toward IYA2009", Education and Public Outreach - A Changing World: Creating Linkages and Expanding Partnerships, Astronomical Society of the Pacific Conference Series 389, eds. C. Garmany, M.G. Gibbs, J.W. Moody, 2008.

2 Pompea, S. M., Walker, C. E., and Sparks, R. T. "Knowledge and Wonder: Engagements with Light and Color in the Hands-On Optics Project," in Exemplary Science in Informal Education Settings: Standards-Based Success Stories, edited by R. Yager and J. Falk, 47-70, NSTA Press (2008).

3 Walker, C. E., Sparks, R. T., and. Pompea, S. M, "Optics Education in the International Year of Astronomy," in Proceedings Education and Training in Optics and Photonics (2007).

4 Pompea, S. M. and Nofziger, M. J., "Resources on Optics in Middle School Education”, Proc. SPIE: 1995 International Conference on Education in Optics, Edited by M. J. Soileau, 2525, (1995)

5 Pompea, S. M. and Gould, A., [Invisible Universe: The Electromagnetic Spectrum from Radio Waves to Gamma Rays], Great Explorations in Math and Science (GEMS) Series, Lawrence Hall of Science, Berkeley, CA (2003).

6 Pompea, S. M., Walker, C.E., and Offerdahl, E., "Teaching the Electromagnetic Spectrum with the Invisible Universe GEMS Guide", 8th International Conference on Education and Training in Optics and Photonics, (2003).
} 
7 Pompea, S.M. and Gek, T. K., "Optics in the Great Exploration in Math and Science (GEMS) Program: A Summary of Effective Pedagogical Approaches", Proc. SPIE, Vol. 4588 (2002).

8 Pompea, S. M., Fienberg, R., Deustua, S., and Isbell, D., "Telescope Kits \& Optics Challenges for the International Year of Astronomy 2009 ", [Education and Public Outreach - A Changing World: Creating Linkages and Expanding Partnerships], Astronomical Society of the Pacific Conference Series 389, eds. C. Garmany, M.G. Gibbs, J.W. Moody, (2008).

9 Hall-Wallace, M., Regens, N. L., and Pompea, S. M., "Design of a Professional Development and Support Program for Future Photonics Industry Team Leaders", Proc. SPIE, 4588 (2002).

10 Pompea, S. M., Dokter, E. F., Walker, C. E., and Sparks, R. T., "Using Misconceptions Research in the Design of Optics Instructional Materials and Teacher Professional Development Programs", Proceedings Education and Training in Optics and Photonics 2007, Ottawa, Canada, (2007).

11 E. F. C. Dokter, S. M. Pompea, R. T. Sparks, C. E. Walker, “The Development of Formative Assessment Probes for Optics Education”, Proceedings SPIE: Optics Education and Outreach, Vol. $7783,2010$.

12 Pompea, S. M., Pfisterer, R. N., Ellis, K. S., Arion, D. N., Fienberg, R. T., “Optical and System Engineering in the Development of a High-Quality Student Telescope Kit”, Proc. SPIE: Modeling, Systems Engineering, and Project Management for Astronomy IV (2010).

13 C. Walker and S. M. Pompea, "National Education Program for Energy Efficient Illumination Engineering, Proceedings SPIE: Eco-Photonics 2011: Sustainable Design, Manufacturing, and Engineering Workforce Education for a Green Future, March 29, 2011, Strasbourg, France

14 S. M. Pompea, L. W. Fine, and P. Meystre, "Photonics Education for a Green Future: Connecting the Dots of the Arizona STEM Education Experiment, Proceedings SPIE: Eco-Photonics 2011:

Sustainable Design, Manufacturing, and Engineering Workforce Education for a Green Future, March 29, 2011, Strasbourg, France

15 Aerospace and Defense Commission's Annual Reports, 2008 Commission Report at http://www.azcommerce.com/Councils/ad_reports.htm

16 S. M. Pompea, R. T. Fienberg, D. N. Arion, T. C. Smith, D. Isbell, “Progress on Creating the Galileoscope for the International Year of Astronomy 2009”, Preparing For The International Year Of Astronomy: A Hands-On Symposium, ASP Conference Series Volume 400, M. G. Gibbs, J. Barnes, J. Manning, and B. Partridge, eds., 2008.

17 S. M. Pompea, R. N. Pfisterer, K. S. Ellis, D. N. Arion, R. T. Fienberg, "Optical and System Engineering in the Development of a High-Quality Student Telescope Kit”, Proceedings SPIE: Modeling, Systems Engineering, and Project Management for Astronomy IV, 2010.

18 www.aura-astronomy.org/nv/Astronomy\%20Beat-WHSP.pdf

19 Lazarowitz, R. and Tamir, P., "Research on Using Laboratory Instruction in Science, in [Handbook of Research on Science Teaching and Learning], edited by D. L. Gabel, Macmillan, (1994).

Proc. of SPIE Vol. $848184810 \mathrm{~F}-7$ 